\title{
Simulation modeling for urban ecology maintenance of environmental comfort level - evidence from the city of Rostov-on-Don
}

\author{
Svetlana Sheina* and Karina Yudina \\ Don State Technical University, Department of City Planning and Urban Development, 344019, \\ Rostov-on-Don, Russia
}

\begin{abstract}
The article touches upon the issue of simulation modeling used as an instrument of managerial decision making in the field of urban planning and development. Modeling is carried out by means of modern IT in software package ESRI ArcGIS 10.1 and for the purposes of information-analytical procurement of complex improvement process and ecological reconstruction of urban territories, urban ecology decision making, and development of ecological monitoring system in urban territories. Simulation model constructed on the basis of the suggested method allows to monitor specific changes in the surveyed environment in the context of gradual implementation of complex assessment and greening activities.
\end{abstract}

\section{Simulation modeling as an instrument of managerial decision making}

Managerial decision making based on forecasting of events is one of the most significant directions in the field of control automation in urban development. Lack of reliable data about various factors having an impact on sustainable development of specific territories hinders source data collection, its evaluation and revealing of its development dynamics, and, consequently, hampers the process of constructive decision making for managing the above mentioned territories. [1] One of the solutions of this problem is adopting of modern geoinformation technologies to management processes.

Simulation modeling method permits to forecast different case scenarios of implementing various solutions for urban development and improvement. It gives an opportunity to conduct a number of experiments on the monitored object or territory before the project development is completed, which has been recently considered impossible.

The core of this method is simulation modeling of the monitored object which can be numerously modernized and modified in order to be adjusted to the changing conditions. Besides, this model allows to monitor particular alterations of the system caused by modifying certain parameters, and, thus, to forecast its future development.

\footnotetext{
Corresponding author: rgsu-gsh@mail.ru
} 


\section{Methods of simulation modeling for urban ecology maintenance of environmental living comfort level}

Methods of simulation modeling for urban ecology maintenance of environmental living comfort level are targeted at information-analytical procurement of complex urban development and ecological reconstruction of urban territories, urban ecology decisionmaking, and development of ecological monitoring system for observing the state of urban territories.

Simulation model comprises three groups of source data, modeling unit and data output unit.

Source data for simulation modeling includes the three modules of source data:

1) Information model for enhancing environmental living comfort as well as data obtained by means of it.

2) Data about long-term territory development according to the general plan. Aggravated estimation of demand concerning amenities and greening is carried out for the regions of built-up areas. The obtained data forms the database of urban ecology parameters for built-up areas. The above-mentioned areas on a par with the attached database are plotted in electronic map of a municipal entity.

3) Data about the actual amenities and greening that is plotted in electronic map of a municipal entity.

In order to be used as source data of a model, any data concerning the actual urban greening objects is to pass the stage of preliminary spatial analysis according to the methods offered by the authors [3].

Spatial analysis of density of greening objects distribution is carried out by ESRI ArcGIS 10.1 system through applying methods of geostatistical analysis on the basis of the additional module Geostatistical Analyst. In this case geostatistic analysis allows to gain a more accurate insight into the density of urban greening distribution.

Simulation model for urban ecology maintenance of environmental comfort level contributes to spatial analysis of urban development processes carried out in the monitored areas. Moreover, the above mentioned model gives an opportunity to forecast territory development in regard to improving environmental comfort level by means of implementing various combinations of entry parameters. 


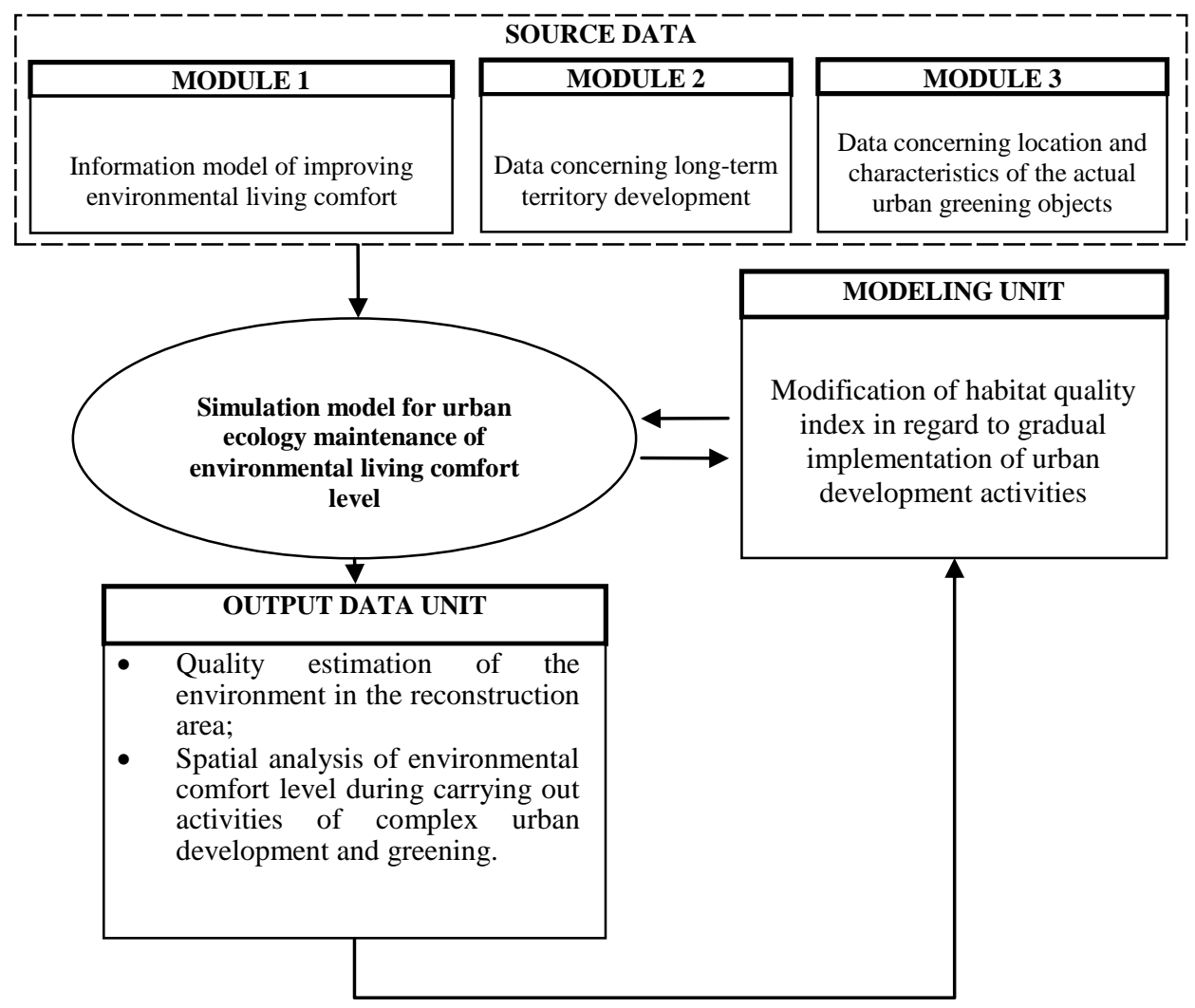

Fig. 1. Diagram representing the functioning of simulation model for urban ecology maintenance of environmental living comfort level during reconstruction of built-up area

Within a framework of the given research the authors have developed a classification of complex urban development and greening activities aimed at improving environmental quality. The complex of effective urban ecology activities for territory development is to be chosen in accordance with habitat quality index (Table 1). Urban greening activities include planting vegetation of various types. Additional activities comprise urban development activities aimed at solving the problems that are not affected by greening objects. Additional activities are chosen with due account of requirements concerning problem solving in the field of urban development and improving environmental living comfort in the given area (Fig. 2). 


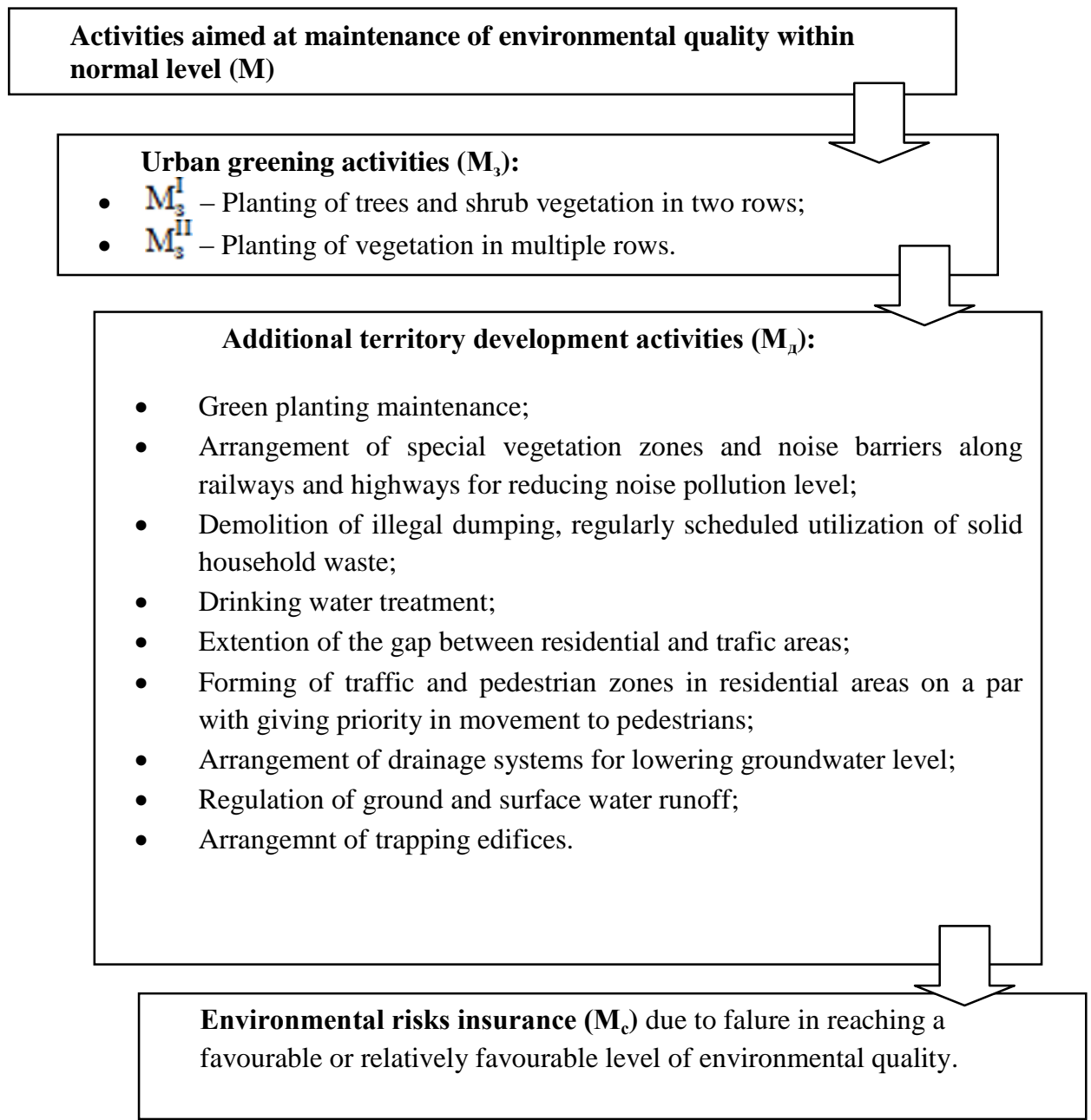

Fig. 2. The structure of urban ecology activities aimed at improving habitat quality

The data represented by the simulation model on a par with spatial analysis of the density of urban greening allowed to determine the quality index in the framework of gradual implementation of complex urban development activities and urban greening activities on the territory of Rostov-on-Don (Fig. 3). 


\section{Colour codes:}

Habitat quality index of area
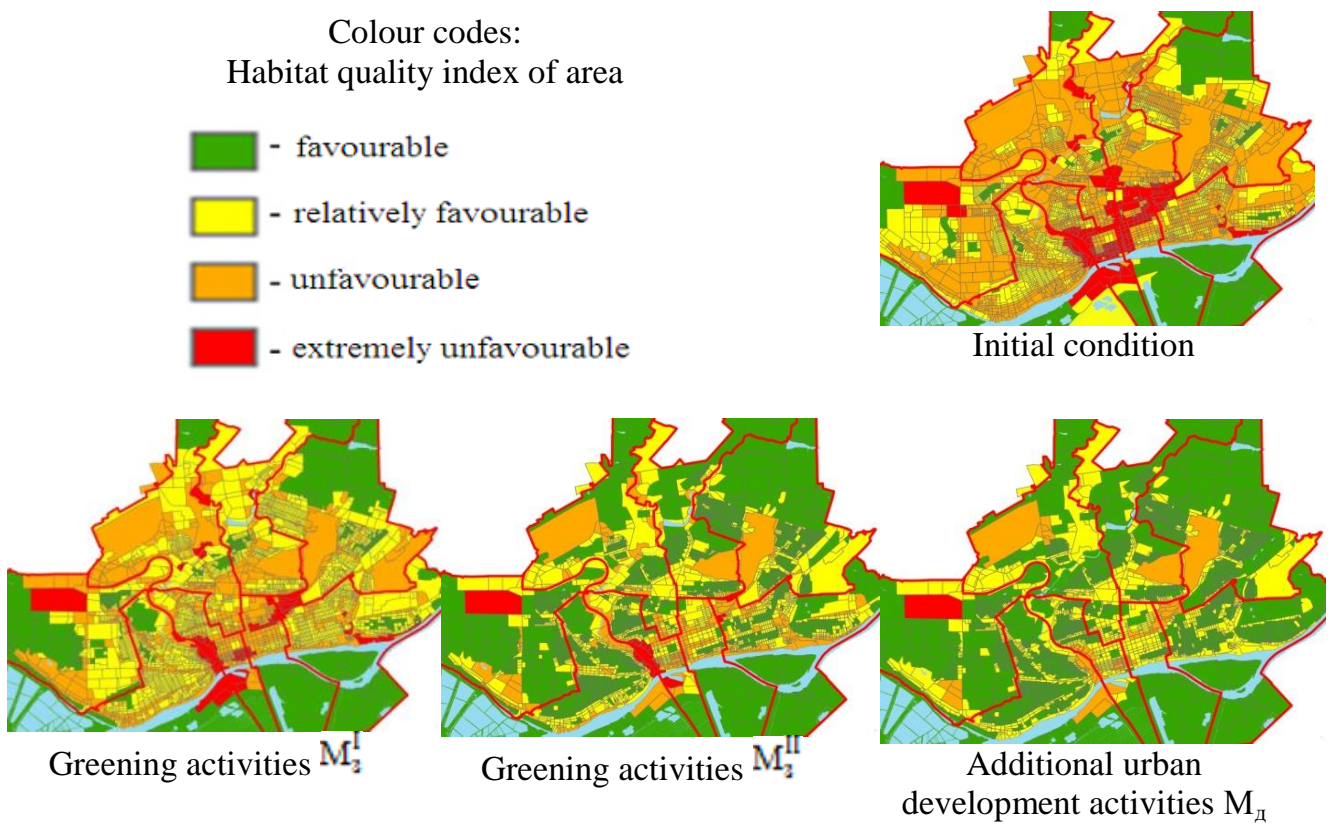

Fig. 3. Modeling of habitat quality index during gradual implementation of complex urban development activities and urban greening activities on the territory of Rostov-on-Don

Alteration of habitat quality index with complex urban development was forecast for assessment areas throughout the entire territory of the city with the exception of large industrial areas and restricted access facilities [4].

\section{The effects and implications of implementing the methods}

In compliance with the adopted classification, simulation modeling for urban ecology maintenance of environmental living comfort level in Rostov-on-Don manifested high efficiency of urban greening activities of the first and the second stages comprising vegetation planting in two and multiple rows. The given method was proved to be a lowcost means of improving environmental living comfort level.

It stands to mention, however, that urban greening activities in the area of historic city centre are rather laborious and hard to implement due to increased urban density, narrow streets and roads, and densely laid utility networks. First and foremost, these conditions pose the necessity of preserving the actual greening objects and upgrading the punishment for illegal demolishing and damaging of vegetation [5]. Implementation of additional urban development activities is to be principal in pursue of improving environmental living comfort level in the city centre of Rostov-on-Don. The same objective requires solving the problems with arrangement of rainfall runoffs, demolishing illegal dumping of solid household waste, and developing a modern and comfortable municipal public transport network and park and ride facilities.

The actual public transport network does not conform to present-day requirements. Its major part consists in minibuses functioning as public taxis with fixed routes. Technical state and quality of the vehicles is primarily in a deplorable state. These factors altogether cause the majority of people to use private transport for daily trips to the city centre, the planning pattern of which was designed as far as in the end of the nineteenth - beginning of 
the twentieth century and is not appropriate for such an intense load [5]. A great step in improving environmental situation in the historic city centre of Rostov-on-Don can be taken by forming primacy of public transport over the private transport.

Simulation model developed through applying modern geoinformation technologies allows to clearly and promptly demonstrate the possible prospects of territory development in Rostov-on-Don concerning improving environmental comfort level by means of complex assessment and greening activities.

\section{References}

1. Yu.N. Truhachev, The General theory of urban systems (methodological concept), (2006)

2. S.G. Sheina, K.V. Yudina, Development of information model of increasing the environmental living comfort during built-up areas reconstruction, J. of Int. Sc. and Pract. Conf. Proc. «Sustainable development of territories», pp. 88-92, (2018)

3. S.G. Sheina, K.V. Yudina, Spatial analysis technique of the greenery distribution density in the reconstruction of built-up territories, Engineer. J. of Don, 3, (2018)

4. S.G. Sheina, L.L. Babenko, R.B. Matveiko Ecological reconstruction of urban territories, (2013)

5. V.S. Vagin, S.G. Sheina, K.V. Chubarova, Problems of the spatial organization of cities with a especially accentuated historical center on the example of the city of Rostov-onDon, int. J. "Naukovedenie", 7(3), (2015) 